\title{
ORIGINAL CONTRIBUTION Transmitted Torque Analysis of Coaxial Magnetic Gears with Different Pole-Pair Numbers
}

\author{
Yi-Chang $\mathrm{Wu}^{1 *}$, Mi-Ching Tsai ${ }^{2}$, Hao-Pin $\mathrm{Wu}^{3}$ \\ ${ }^{1,3}$ Department of Mechanical Engineering, National Yunlin University of Science and Technology, Douliu, Taiwan \\ ${ }^{2}$ Department of Mechanical Engineering, National Cheng-Kung University, Tainin, Taiwan
}

\begin{abstract}
Transmitted torque is an important performance index of coaxial magnetic gears. This study focuses on the effects of pole-pair numbers on the maximum torque capacity and torque ripple of coaxial magnetic gearsowing to the magnetic resistance between the pole piece and the medium of air; a torque ripple is generated during magnetic gear operation. In magnetic gear design, maximum torque capacity is considered the higher, the better, and the torque ripple should be the lower, the better. A commercial Finite-element analysis software ANSYS/Maxwell 2D is applied to simulate the transmitted torque and torque ripple of coaxial magnetic gears by solving the magnetic field, and mechanical motion coupled models. Model parameters, including size and inertia, are designed via the Autodesk/Inventor. The results of finiteelement analysis have shown that there are certain relationships between pole-pair numbers and torque performance. It reveals that the sum of the pole-pair numbers is inversely proportional to the maximum torque capacity; the differences of maximum torque between different polepair number designs could be up to $82 \%$. However, the torque ripple has not been proven for the relationship. For future research, the torque capability per cost would be necessary for magnetic gear product, especially when the price of rare earth metal is seen rising in the past years. Also, the efficiency of magnetic gear is still important for powertrain system, but it's not easy to reach both high torque and efficiency, owing to the flux saturation problem. The balance of torque capacity, efficiency, and cost would be the next challenge.
\end{abstract}

Index Terms - Magnetic Gear, Finite-Element Analysis, Transmitted Torque

Received: 2 March 2019; Accepted: 18 April 2019; Published: 26 June 2019

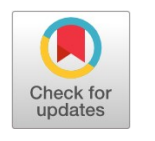

(C) 2019 JITDETS. All rights reserved.

\section{INTRODUCTION}

Magnetic gears are considered to have the same function as conventional gearboxes with a non-contact power transmitting solution. In many powertrains, such as vehicles or motors, due to the wear of the mechanical gearbox, engineers have come up with many approaches to enhance the durability of the gear (e.g., lubrication and tolerance management). In a magnetic gear, all of the rotors and flux-modulators are separated, which provides frictionless operation [1]. Many industrial applications of magnetic gears are being revealed in [2]; some of the characteristics were reported in [3] with constraint visualization on the Pareto set, which provides a comprehensive optimization method and the influences of each characteristic. Compared to conventional gear, the problem of low torque density shows up when the magnetic gear is applied for many powertrain designs; in order to overcome the torque density issue, a novel magnetic gear toward a higher torque density has been presented [4]. In general, magnetic gears have a lower torque density compared with a conventional gearbox; the torque density of magnetic gears found in the literature ranges from 70 to $162 \mathrm{Nm} / \mathrm{L}[5,6,7,8]$. As already known, the torque density varies depending on magnetic gear design, an optimum design for SPM type magnetic gear. Research $[9,10,11]$ shows how to optimize the

\footnotetext{
* Corresponding author: Yi-Chang Wu

†Email: wuyc@yuntech.edu.tw
}

transmitted torque. As long as the torque density can be optimized, the next step will be ensuring the efficiency of power transmission, an experimental test report of efficiency improvement [12], and the high-efficiency in-wheel magnetic gear [13] shows the highly potentiated magnetic with the maximum efficiency at around $94.4 \%$. Also, the applications for high speed and vibration motor systems and the skewed cogging torque optimization method have been discussed $[14,15,16]$.

In order to reach higher torque capability at the magnetic gear design section, this paper focuses on optimization design of pole-pair numbers and reveals the pattern where pole-pair numbers influence torque capability. The geometry of the magnetic gear is fixed except the pole-pair numbers with the angle of each magnet and pole-piece; transmitted torque and torque ripple are calculated by two-dimensional finite element analysis (2D-FEA). Next, the torque-related characteristics have been discussed, where the pole-pair numbers significantly affect the torque capability by over $82 \%$. Finally, the uncertainty of torque ripple and other issues are concluded. 


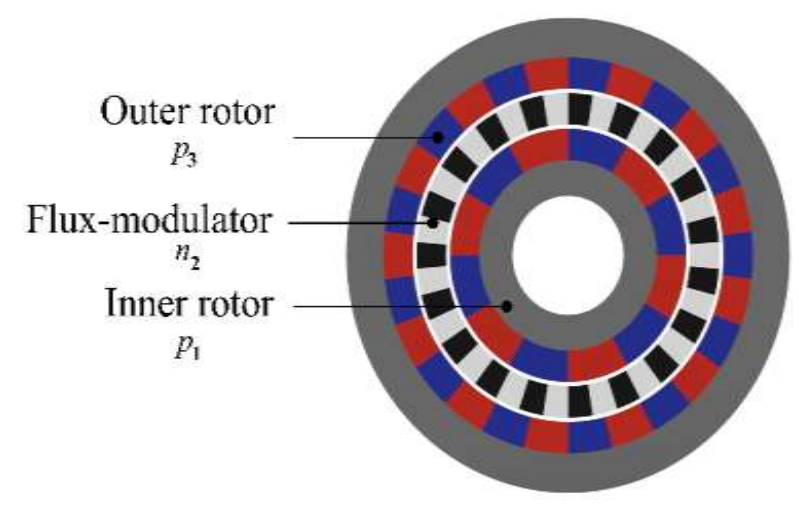

Fig. 1. Cross-section of the coaxial magnetic gear

Fig. 1 shows the cross-section of a coaxial magnetic gear. The coaxial magnetic gear is made up of three parts: the inner rotor, flux-modulator, and outer rotor. The definition of pole-pair numbers is the sum of the polepairs of each part, where $\mathrm{p}_{1}$ indicates the pole-pairs of the inner rotor, $\mathrm{n}_{2}$ is the number of pole-pieces of the flux-modulator, and $\mathrm{p}_{3}$ represents the pole-pairs of the outer rotor. The relationship between the pole-pair numbers Eq. 1 must follow the rule:

$$
n_{2}=p_{1}+p_{3}
$$

Also, it can be shown that the angular speed relationship between each part $[11,12]$ is given by Eq. 2 :

$$
\omega_{1}=\left(\frac{n_{2}}{p_{1}} \omega_{2}\right)+\left(\frac{n_{3}}{p_{1}} \omega_{3}\right)
$$

where $\omega_{1}, \omega_{2}, \omega_{3}$ are the rotational speeds of the inner rotor, fluxmodulator, and outer rotor, respectively.

The three components must respect relation Eq. 1. In the case using the inner rotor as input, the flux-modulator as output, and the outer rotor as fixed, it is then possible to define the gear ratio $\mathrm{G}_{m}$ (Eq. 3):

$$
\omega_{3}=0 \rightarrow G_{m}=\frac{\omega_{1}}{\omega_{2}}=\frac{n_{2}}{p_{1}}
$$

The magnetic gear can regulate torque and gear ratio as desired, even provides better efficiency compared to conventional gear. Hence, the magnetic gear with more torque in a compact space will be much attractive to the powertrain design.

\section{COAXIAL MAGNETIC GEAR}

As shown in Fig. 1, a typical coaxial is applied in this research. In this constructive model, all the geometric parameters of the magnetic gear are fixed, as shown in Table I.

TABLE I

GEOMETRICAL PARAMETERS OF MAGNETIC GEAR

\begin{tabular}{llll}
\hline \hline & Description & Value & Unit \\
\hline \multirow{5}{*}{ Inner rotor } & Pole pairs, $p_{1}$ & Table II & \\
& Outer diameter & 64 & $\mathrm{~mm}$ \\
& Thickness of magnet & 10 & $\mathrm{~mm}$ \\
& Thickness of yoke & 10 & $\mathrm{~mm}$ \\
& Air gap & $17 \mathrm{Mm}$ & \\
Flux-modulator & Pole pieces, $n_{2}$ & Table II & \\
& Thickness & 8 & $\mathrm{~mm}$ \\
& Pole pairs, $p_{3}$ & Table II & \\
Outer rotor & Outer diameter & 120 & $\mathrm{~mm}$ \\
& Thickness of magnet & 8 & $\mathrm{~mm}$ \\
& Thickness of yoke & 10 & $\mathrm{~mm}$ \\
& Air gap & 1 & $\mathrm{~mm}$ \\
& Model depth, L & 60 & $\mathrm{~mm}$ \\
\hline \hline
\end{tabular}

TABLE II

DIFFERENT POLE-PAIR NUMBERS DESIGN OF ANALYSIS

\begin{tabular}{lllll}
\hline \hline No. & $p_{1}$ & $n_{2}$ & $p_{3}$ & Sum of pole-pair numbers \\
\hline 1 & 8 & 25 & 17 & 50 \\
2 & 11 & 24 & 13 & 48 \\
3 & 11 & 23 & 312 & 46 \\
4 & 8 & 22 & 14 & 44 \\
5 & 5 & 21 & 16 & 42 \\
6 & 7 & 20 & 13 & 40 \\
7 & 6 & 19 & 13 & 38 \\
8 & 7 & 18 & 11 & 36 \\
9 & 4 & 17 & 13 & 34 \\
10 & 7 & 17 & 10 & 34 \\
11 & 7 & 16 & 9 & 32 \\
12 & 4 & 15 & 11 & 30 \\
13 & 3 & 14 & 11 & 28 \\
14 & 3 & 13 & 10 & 26 \\
15 & 5 & 12 & 7 & 24 \\
16 & 3 & 11 & 8 & 22 \\
17 & 3 & 10 & 7 & 20 \\
18 & 2 & 9 & 7 & 18 \\
19 & 3 & 8 & 5 & 16 \\
20 & 2 & 7 & 5 & 14 \\
21 & 2 & 5 & 3 & 10 \\
\hline \hline
\end{tabular}

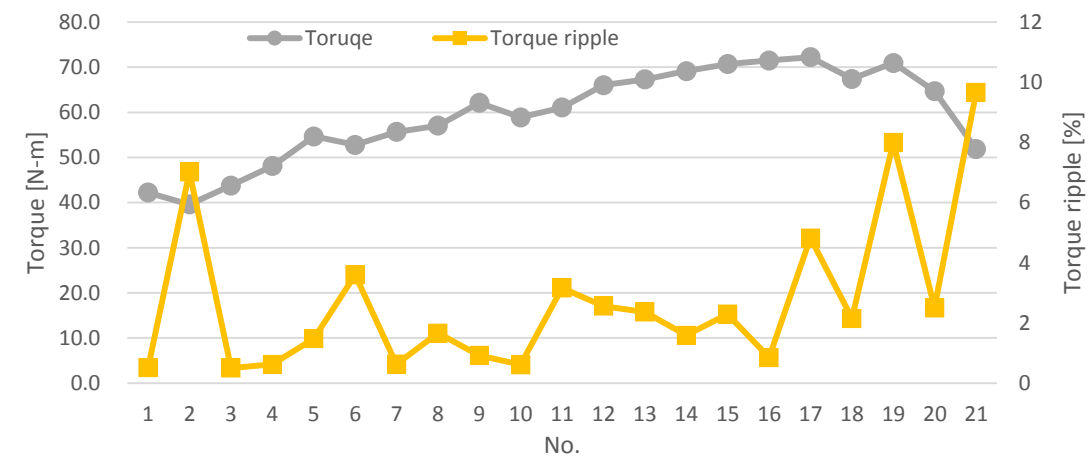

Fig. 2. Maximum torque and torque ripple of output (flux-modulator) 


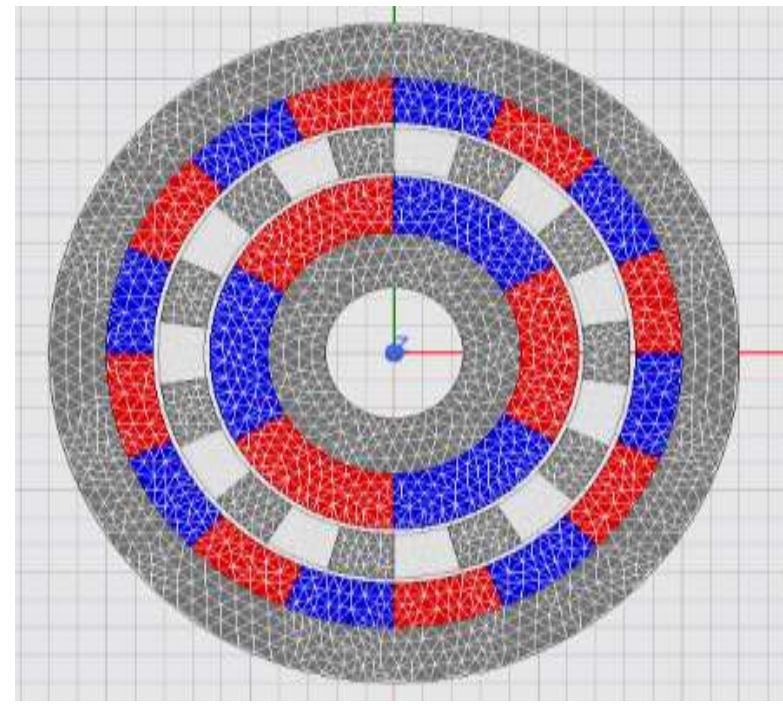

Fig. 3. 2D-FEA meshed model no. 16 of the magnetic gear

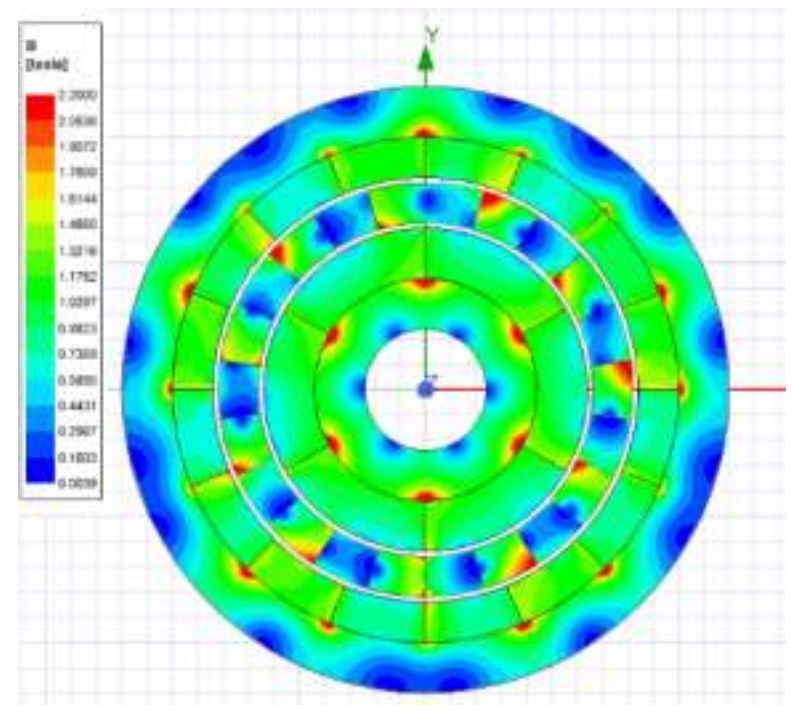

Fig. 4. View of flux density distributions with model no.16

It is assumed that the magnet and the flux-modulator are spanned equally; the angle of the inner rotor and outer rotor magnet is given by (Eq. 4) and (Eq. 5); the flux-modulator is combined with pole-piece and air as given by (Eq. 6), where $\theta_{1}$ is the angle of inner rotor magnet, $\theta_{3}$ is the angle of outer rotor magnet, and $\theta_{2}$ is the angle of pole-piece. Pole-pair numbers and the angle of each component are the variables used in this paper.

$$
\begin{aligned}
& \theta_{1}=360^{\circ} /\left(2 p_{1}\right) \\
& \theta_{3}=360^{\circ} /\left(2 p_{3}\right) \\
& \theta_{2}=360^{\circ} /\left(2 n_{2}\right)
\end{aligned}
$$

In order to compare the differences between the different setups of the pole-pair numbers, the main objective is to verify the pattern of torque changes rather than find out a specified optimum design. The sum of the pole-pair numbers of each model ranged from 10 to 50 , and the polepair numbers of the inner rotor ranged from 2 to 11, as shown in Table II; these numbers are commonly used in magnetic gear design. The pole-pair numbers of the flux-modulator and outer rotor are designed by the relation among three components (Eq. 1). Each of the pole-pair number designs has been grouped from No. 1 to No. 21. Fig. 3 shows the 2D-FEA meshed model no. 16 of the magnetic gear. Each of the mesh element sizes was defined as the individual component's radial length divided by 3 with the inside selection mesh operation. The flux distribution of 2D-FEA model is shown in Fig. 4; it shows the saturation level of each part. The most concerned issue will be the saturation of flux-modulator; it has been proved that the saturation affects torque capability and efficiency [3]. In Fig. 4, the flux density is saturated at the iron yoke and flux-modulator (in red color); it's obvious that the saturation happens near to the edge of the magnet, which is reasonable because of the flux centralization of $N$ and $S$ pole magnet. The saturation could be modified with a different geometric design; one of the common methods is to chamfer the edge of the flux-modulator, which could spread the flux density more evenly to avoid flux centralization. Despite this, it's certainly predictable that the torque capacity will decrease when any kind of approach has applied for the flux density decentralization.

\section{INFLUENCE OF CHANGING POLE-PAIR NUMBERS DESIGN}

The analysis conditions of the maximum torque and torque ripple are in the same setup, where the inner rotor and flux-modulator rotate at a specific rpm according to (Eq. 2) and (Eq. 3). The torque ripple is calculated to be (Eq.7):

$$
\text { torqueripple }(\%)=\frac{\left(T_{\max }-T_{\min }\right)}{T_{\text {avg }}} \times 100 \%
$$

where $T_{m} a x$ and $T_{m}$ in represent the maximum and minimum torque values and $T_{a} v g$ is the average torque.

\section{A. Maximum Torque}

As shown in Fig. 2, it is obvious that the maximum torque has been affected by the sum of the pole-pair numbers, especially from No. 12 to No. 17. The lower the pole-pair number, the higher the torque. Though the overall pattern between the pole-pair numbers and maximum torque seems clear, some results of analyses show that this kind of relationship doesn't work from No. 19 to No. 21. It might be the limitation of the torque capability optimum design, the reason why the torque has decreased as indefinite. However, we have already discovered that the maximum torque could be optimized in a certain range of pole-pair numbers. The differences in maximum torque are up to $82 \%$ compared with those from No. 2 \& No. 17.

\section{B. Torque Ripple}

To minimize the torque ripple, the optimization of the pole-pair numbers has been done in [13]. It shows that the higher pole-pair numbers should obtain a lower torque ripple. However, Fig. 2 shows that the torque ripple does not respond linearly. Also, the relationship between the torque ripple and the pole-pair numbers is ambiguous. The comparisons from No.1 to No. 21 show that the overall torque ripple increased when the pole pair numbers decreased, but as we can see for No. 16 to No. 21 , the trend is not specific, while the differences of each could be both positive and negative. It's hard to tell if the pole-pair numbers really affect the torque ripple from these results.

\section{Gear Ratio}

In previous sections $\mathrm{A}$ and $\mathrm{B}$, the relationship between torque capacity and pole pair numbers has been clarified. But the gear ratio is yet confirmed to be torque-related, where the gear ratio is defined as (Eq. 8):

$$
\text { Gearratio }=\frac{n_{2}}{p_{1}}
$$




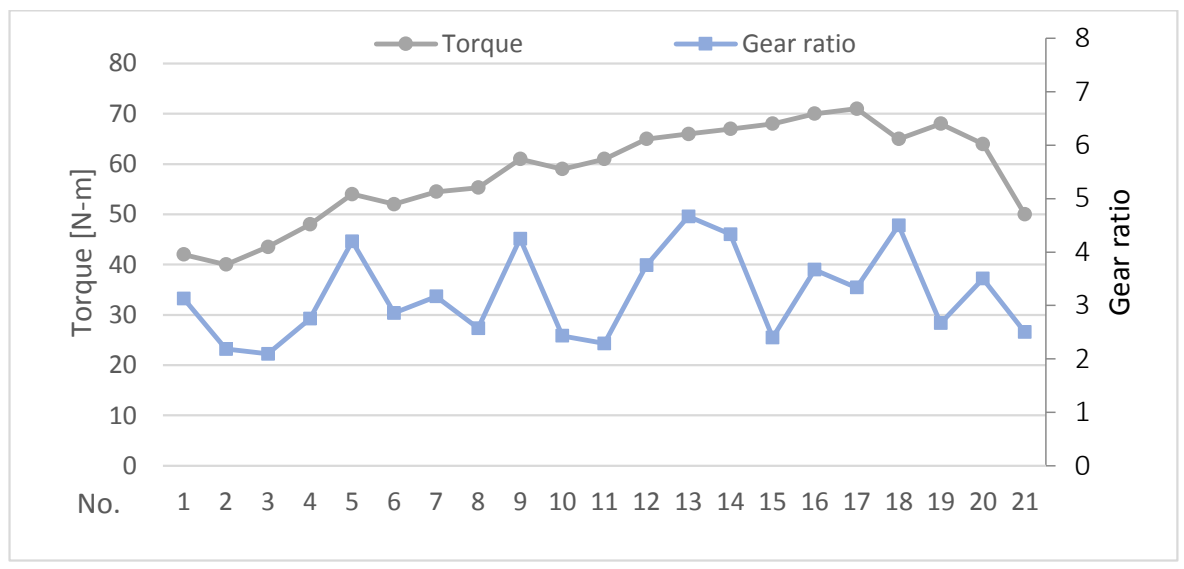

Fig. 5. Maximum torque and gear ratio

The gear ratio is calculated to be the pole pair numbers of fluxmodulator divided by the pole pair numbers of inner rotor; the magnetic gear is set to be single speed ratio (direct drive), where the outer rotor is assumed to be fixed. The gear ratio with the torque capacity is shown in Fig. 5; although it seems to be affecting torque capacity directly from No. 3 to No. 5, and No.17 to No.2, it's still hard to tell whether the gear ration affects the torque capacity or not without further information.

\section{Optimum Design}

In other recent researches, there are plenty of optimum designs for magnetic gear $[17,18,19]$. These papers reveal the optimum geometric design either for high torque capacity or efficiency. However, the pole-pair numbers optimum design has yet to be indicated. The challenge for the optimization of magnetic gear is considered with many complex characteristics; it's really difficult to create a comprehensive optimum design. In this research, the influence of changing pole-pair numbers has been confirmed. Torque capacity will have a huge difference of $82 \%$ compared with model No. 2 \& No. 17. Based on that, how to get an optimum design for the best torque capacity by modifying the pole-pair numbers will be the next issue.

\section{CONCLUSION AND IMPLICATIONS}

In this paper, the relationship between maximum torque and polepair numbers has been analyzed. The best design was No. 17, which had the highest torque. However, the torque ripple seems to be terribly high as well. There are 7 designs that have a lower than $1 \%$ torque ripple, which are No. $1,3,4,7,9,10$, and 16 . According to the analysis results, No. 16 with $\left(p_{1}, n_{2}, p_{3}\right)=(3,11,8)$ reached the 2 nd highest torque capacity with $71.5 \mathrm{~N}-\mathrm{m}$ and the 6 th lowest torque ripple at $0.85 \%$, while its performance maintained a high maximum torque and torque ripple under $1 \%$. Relatively, it's the best design of all pole-pair number designs. However, some of the designs of pole-pair numbers will have trouble in manufacturing due to the angle of the magnet, which is usually under 90 degrees. In addition, the material of flux-modulator affects the torque capacity and efficiency significantly; so, the research of magnetic material is needed for the best solution of flux-modulator.

In some cases, the flux-modulator could be the biggest challenge in the design and manufacture section. Yet many uncertainties remain regarding the relationship of how pole-pair numbers affect the torque ripple. Here are some parameters that might be key factors affecting the torque ripple:
- The gear ratio between the inner rotor, flux-modulator, and outer rotor

- The shape of the magnet and pole-piece

- The geometric size of all constructive parts

- The rotating speed and loading

- Mechanical Damping

The authors believe that using multiphysics models of magnetic gears would enhance the accuracy of predicting the relationship between pole-pair numbers and torque ripple. For future research, the torque capability per cost would be necessary for magnetic gear product, especially when the price of rare earth metal is seen rising in the past years. Also, the efficiency of magnetic gear is still important for powertrain system, but it's not easy to reach both high torque and efficiency, owing to the flux saturation problem. The balance of torque capacity, efficiency, and cost would be the next challenge.

\section{ACKNOWLEDGEMENT}

Thanks to the Projects MOST 107-2622-8-006-015 and MOST 107-2218-E-006-002 of the Ministry of Science and Technology for financial support, so that the research work can be finished smoothly without concerns about research resources.

\section{Declaration of Competing Interest}

The authors declare that they have no known competing financial interests or personal relationships that could have appeared to influence the work reported in this paper.

\section{References}

[1] K. Marat, Y. Assem, M. Bakhytzhan, and K. Peter, “Theoretical and experimental researches on development of new construction of winddriven generator with flux concentrator," Journal of Advances in Technology and Engineering Research, vol. 2, no. 3, pp. 100-104, 2016. doi: https://doi.org/10.20474/jater-2.3.4

[2] Y. Ando, "Current development trend of magnetic gears," Journal of the Japan Society of Applied Electromagnetics and Mechanics, vol. 24, no. 2, pp. 67-72, 2016. doi: https://doi.org/10.14243/jsaem.24.67

[3] M. Filippini and P. Alotto, "Coaxial magnetic gear design and optimization," IEEE Transactions on Industrial Electronics, vol. 64, 
no. 12, pp. 9934-9942, 2017. doi: https://doi.org/10.1109/tie.2017. 2721918

[4] X. Yin, P.-D. Pfister, and Y. Fang, "A novel magnetic gear: Toward a higher torque density," IEEE Transactions on Magnetics, vol. 51, no. 11, pp. 1-4, 2015. doi: https://doi.org/10.1109/tmag.2015. 2436058

[5] K. K. Uppalapati, J. Z. Bird, J. Wright, J. Pitchard, M. Calvin, and W. Williams, "A magnetic gearbox with an active region torque density of 239nm/l," in IEEE Energy Conversion Congress and Exposition (ECCE), Pittsburgh, PA, 2014

[6] M. Johnson, M. C. Gardner, H. A. Toliyat, S. Englebretson, W. Ouyang, and C. Tschida, "Design, construction, and analysis of a large-scale inner stator radial flux magnetically geared generator for wave energy conversion," Transactions on Industry Applications, vol. 54, no. 4, pp. 3305-3314, 2018. doi: https://doi.org/10.1109/tia.2018.2828383

[7] M. Johnson, M. C. Gardner, and H. A. Toliyat, "Design comparison of $\mathrm{NdFeB}$ and ferrite radial flux surface permanent magnet coaxial magnetic gears," Transactions on Industry Applications, vol. 54, no. 2, pp. 1254-1263, 2018. doi: https://doi.org/10.1109/tia.2017.2765301

[8] L. Jing, J. Gong, Z. Huang, T. Ben, and Y. Huang, "A new structure for the magnetic gear," IEEE Access, vol. 7, pp. 75 550-75 555, 2019. doi: https://doi.org/10.1109/access.2019.2919679

[9] D. S. Hasan and I. Hamarash, "Calculation of angular velocity, angular acceleration and torque of two common point rigid bodies using IMU," Journal of Applied and Physical Sciences, vol. 3, no. 2, pp. 58-64, 2017. doi: https://doi.org/10.20474/japs-3.2.3

[10] M. Tsai and L. Ku, " $3 \mathrm{~d}$ printing based design of axial flux magnetic gear for high torque density," in International Magnetics Conference (INTERMAG), Beijing, China, 2015. doi: https://doi.org/10.1109/ intmag.2015.7156626

[11] W. N. Fu and L. Li, "Optimal design of magnetic gears with a general pattern of permanent magnet arrangement," Transactions on Applied Superconductivity, vol. 26, no. 7, pp. 1-5, 2016. doi: https: //doi.org/10.1109/tasc.2016.2587279
[12] K. Aiso, K. Akatsu, and Y. Aoyama, "Reluctance magnetic gear and flux switching magnetic gear for high speed motor system," in Energy Conversion Congress and Exposition (ECCE), Cincinnati, OH, 2017.

[13] K. Ito, T. Kadomatsu, and K. Nakamura, "Efficiency improvement of in-wheel magnetic geared motor and feasibility study for walking support machines," in International Electric Machines \& Drives Conference (IEMDC), San Diego, California, 2019. doi: https://doi.org/ 10.1109/iemdc.2019.8785161

[14] N. Semsri., C. Torasa., K. Samerjai., M. Suksombat, and P. Sinpeng, "Electricity-generating wind turbine from electric bicycle motor," International Journal of Technology and Engineering Studies, vol. 2, no. 4, pp. 101-109, 2016. doi: https://doi.org/10.20469/ijtes.2. 40002-4

[15] K. Li, Z. Zhu, and P. Wu, "A reluctance magnetic gear for high speed and vibration motor systems," in 25th International Conference on Mechatronics and Machine Vision in Practice (M2VIP), BadenWurttemberg, Germany, 2018.

[16] G. Jungmayr, J. Loeffler, B. Winter, F. Jeske, and W. Amrhein, "Magnetic gear: Radial force, cogging torque, skewing, and optimization," Transactions on Industry Applications, vol. 52, no. 5, pp. 3822-3830, 2016. doi: https://doi.org/10.1109/tia.2016.2571267

[17] A. Penzkofer and K. Atallah, "Optimisation of magnetic gears for large wind turbines," in 15th International Conference on Environment and Electrical Engineering (EEEIC), Rome, Italy, 2015.

[18] Y. Tian, G. Liu, W. Zhao, and J. Ji, "Design and analysis of coaxial magnetic gears considering rotor losses," Transactions on Magnetics, vol. 51, no. 11, pp. 1-4, 2015. doi: https://doi.org/10.1109/tmag. 2015.2435253

[19] M. C. Gardner, M. Johnson, and H. A. Toliyat, "Analysis of high gear ratio capabilities for single-stage, series multistage, and compound differential coaxial magnetic gears," Transactions on Energy Conversion, vol. 34, no. 2, pp. 665-672, 2019. doi: https://doi.org/10.1109/ tec.2018.2868730 